\title{
Формирование медной контактной сетки на поверхности кремниевых гетероструктурных фотоэлектрических преобразователей
}

\author{
(C) С.Н. Аболмасов ${ }^{1}$, А.С. Абрамов ${ }^{1,2}$, В.Н. Вербицкий ${ }^{1,2}$, Г.Г. Шелопин ${ }^{1}$, А.В. Кочергин ${ }^{1,3}$, Е.И. Теруков ${ }^{1,2,3}$ \\ ${ }^{1}$ ООО „НТЦ тонкопленочных технологий в энергетике“, \\ 194064 Санкт-Петербург, Россия \\ ${ }^{2}$ Физико-технический институт им. А.Ф. Иоффре Российской академии наук, \\ 194021 Санкт-Петербург, Россия \\ ${ }^{3}$ Санкт-Петербургский государственный электротехнический университет „ЛЭТИ“ им. В.И. Ульянова (Ленина), \\ 197376 Санкт-Петербург, Россия \\ E-mail: tem47@mail.ru
}

Поступила в Редакцию 9 декабря 2021 г.

В окончательной редакции 10 января 2022 г.

Принята к публикации 10 января 2022 г.

\begin{abstract}
Представлен сравнительный анализ различных методов формирования медной $(\mathrm{Cu})$ контактной сетки на поверхности кремниевых гетероструктурных фотоэлектрических преобразователей (SHJ ФЭП) в качестве альтернативы стандартному методу трафаретной печати с использованием дорогостоящих серебросодержащих $(\mathrm{Ag})$ паст. Показано, что использование струйной печати для формирования защитных диэлектрических масок на основе органического полимера и тонких буферных металлических слоев для роста Сu-контактной сетки методом электрохимического осаждения позволяет формировать контактную сетку необходимой формы, обладающую достаточной адгезией к поверхности SHJ ФЭП. Используя данный метод, были изготовлены двусторонние SHJ ФЭП (размером $157 \times 157$ мм) с Сu-контактной сеткой, демонстрирующие кпд $=22.9 \%$ и уровень адгезии $3-5 \mathrm{H} / \mathrm{Mм}$ по сравнению с $22.6 \%$ и $1.5-2 \mathrm{H} / \mathrm{Mм}$ при использовании аналогичной контактной сетки на основе $\mathrm{Ag}$-пасты.
\end{abstract}

Ключевые слова: солнечная энергетика, монокристаллический кремний, гетероструктурный фотоэлектрический преобразователь, медная контактная сетка, электрохимическое осаждение, трафаретная и струйная печать.

DOI: $10.21883 /$ FTP.2022.05.52356.9787

\section{1. Введение}

Сегодня наземная солнечная энергетика на 95\% базируется на фотоэлектрических преобразователях (ФЭП) на основе монокристаллического кремния $(c-\mathrm{Si}) p$-типа (так называемых PERC ячейках $p$-типа), которые в массовом производстве практически достигли предела в кпд на уровне $22-23 \%$ [1]. Поэтому общей тенденцией дальнейшего развития является переход к более высокоэффективным технологиям на основе $c$-Si $n$-типа, таким как PERT, TOPCon и SHJ [2]. Среди них гетероструктурная (SHJ) технология обладает, наряду с другими достоинствами (низкотемпературный технологический процесс с наименьшим количеством технологических операций, максимальный фактор двусторонности и т.д.), потенциалом достижения максимальных значений кпд $>26 \%$ [3].

Следует отметить, что в SHJ технологии, как и в остальных $c$-Si фотоэлектрических технологиях, для собирания носителей заряда применяются контактные сетки, наносимые на поверхность ФЭП при помощи трафаретной печати серебросодержащей (Ag) пастой, которая в последствии проходит температурную обработку. Отличительной особенностью SHJ технологии является применение низкотемпературных Ag-паст с температурой отверждения $\sim 200^{\circ} \mathrm{C}$, что существенно ниже температуры плавления Ag. Поэтому проводимость та- ких низкотемпературных Ag-паст является более низкой и осуществляется за счет соприкосновения отдельных микро- и наночастиц $\mathrm{Ag}$, являющихся основой проводящей пасты, зафиксированных в отвержденной полимерной матрице. Из-за специфики технологического процесса и большого содержания Ag стоимость низкотемпературных $\mathrm{Ag}$ паст является выше по сравнению со стандартными высокотемпературными Ag-пастами, используемыми в PERC ФЭП.

В настоящее время вклад себестоимости серебросодержащей пасты в материальную себестоимость $c$-Si солнечных панелей составляет $\sim 10 \%$ и имеет тенденцию к увеличению в связи с подорожанием серебра в последние годы. Дополнительно, как показывают результаты последних исследований, дальнейшее увеличение производства $c$-Si ФЭП до тераваттного (ТВт) уровня в будущем может привести к нехватке серебра и резкому росту его стоимости, что поставит под угрозу дальнейшее развитие наземной солнечной энергетики. Наиболее подходящей альтернативой серебру является медь $(\mathrm{Cu})$. Этот металл широко используется в микроэлектронике и электротехнике в качестве основного материала для изготовления проводников, он почти на 2 порядка дешевле $\mathrm{Ag}$ и его запасы более чем достаточны для ТВт-производства c-Si ФЭП [4]. 


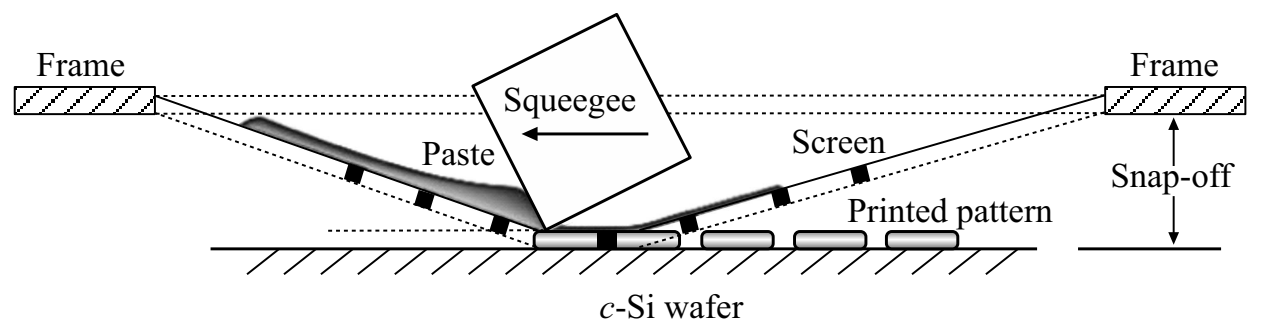

Рис. 1. Схематическое изображение процесса нанесения контактной сетки на $c$-Si ФЭП с помощью метода трафаретной печати.

1 - screen printing

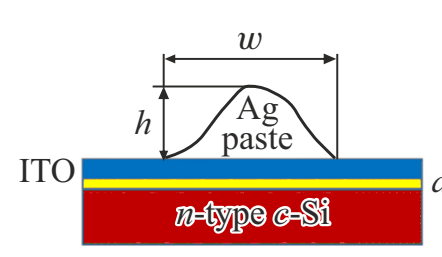

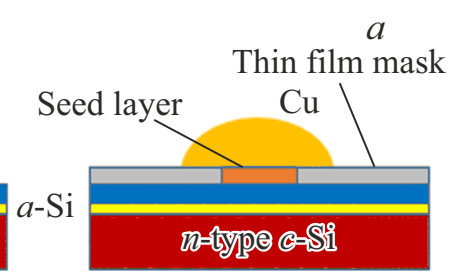

2 - copper plating

$b$

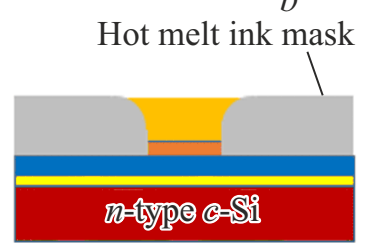

$c$

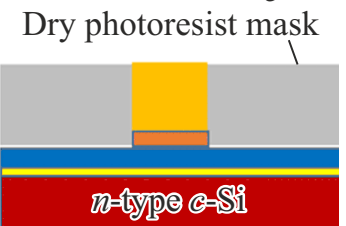

Рис. 2. Схематическое изображение сечения контактной сетки в случае использования (1) трафаретной печати и (2) электрохимического осаждения с использованием различных защитных масок.

На сегодняшний день существует три основных технологии, которые позволяют существенно снизить или полностью исключить использование $\mathrm{Ag}$ в SHJ ФЭП путем ее замены на $\mathrm{Cu}$, такие как Silver Coated Copper Paste $(\mathrm{SCCP} \sim 30 \% \mathrm{Cu})$, Smart Wire Connection Technology (SWCT $\sim 50 \% \mathrm{Cu})$ и Copper Plating $(\mathrm{CP} \sim 100 \% \mathrm{Cu})[5]$. Так как SCCP и SWCT технологии все еще включают в себя стандартный метод трафаретной печати для формирования контактной сетки, то это позволяет только частично сократить количество $\mathrm{Ag}$ в SHJ ФЭП. В то время как электрохимическое осаждение меди - СР-метод, на котором сфокусирована данная статья, позволяет полностью заменить $\mathrm{Ag}$ на $\mathrm{Cu}$, а также имеет дополнительные достоинства по сравнению с методом трафаретной печати, как будет показано далее.

\section{2. Особенности электрохимического осаждения Cu-контактной сетки на поверхность SHJ ФЭП}

Так как при электрохимическом осаждении меди используются электролиты, которые имеют кислотную среду, а внешняя поверхность SHJ ФЭП покрыта прозрачными проводящими слоями из оксидов индия-олова (ITO), то для их защиты от кислотного воздействия и формирования топологии контактной сетки на их поверхности используются защитные диэлектрические маски. С другой стороны, проводимость ITO слоев является недостаточной для равномерного растекания тока по всей поверхности полноразмерных SHJ ФЭП, что в свою очередь приводит к необходимости использования дополнительных металлических слоев, покрыва- ющих ITO. Данные слои также могут улучшать адгезию медной контактной сетки к ITO. Как правило, металлические слои наносятся на поверхность ITO методом магнетронного распыления (PVD), который широко используется для формирования ITO слоев при массовом производстве SHJ ФЭП. Для создания защитных диэлектрических масок могут быть использованы различные методы вплоть до фотолитографии [6], заимствованной из микроэлектроники, где она наряду с электрохимией успешно используется для создания медных контактов в течение нескольких последних десятилетий. Следует, однако, отметить, что производительность современных систем фотолитографии составляет 100 пластин/ч, тогда как производительность современных принтеров трафаретной печати для $c$-Si ФЭП превышает 3000 пластин/ч, а для PVD систем может достигать 10000 пластин/ч [7]. Поэтому в дальнейшем мы будем рассматривать методы создания защитных диэлектрических масок и затравочных металлических слоев, которые совместимы с массовым производством SHJ ФЭП, используя трафаретную печать в качестве эталона.

\section{1. Трафаретная печать}

Трафаретная печать является стандартным методом изготовления контактных сеток для $c$-Si ФЭП, включая SHJ ФЭП. При этом низкотемпературная Ag-паста продавливается сквозь отверстия на поверхности трафарета, которые задают геометрию контактной сетки, как видно на рис. 1.

Как правило, при использовании трафаретной печати контактные дорожки имеют колоколообразную форму (см. рис. 2.1). Однако следует отметить, что с точки зрения минимизации оптических и электрических потерь 

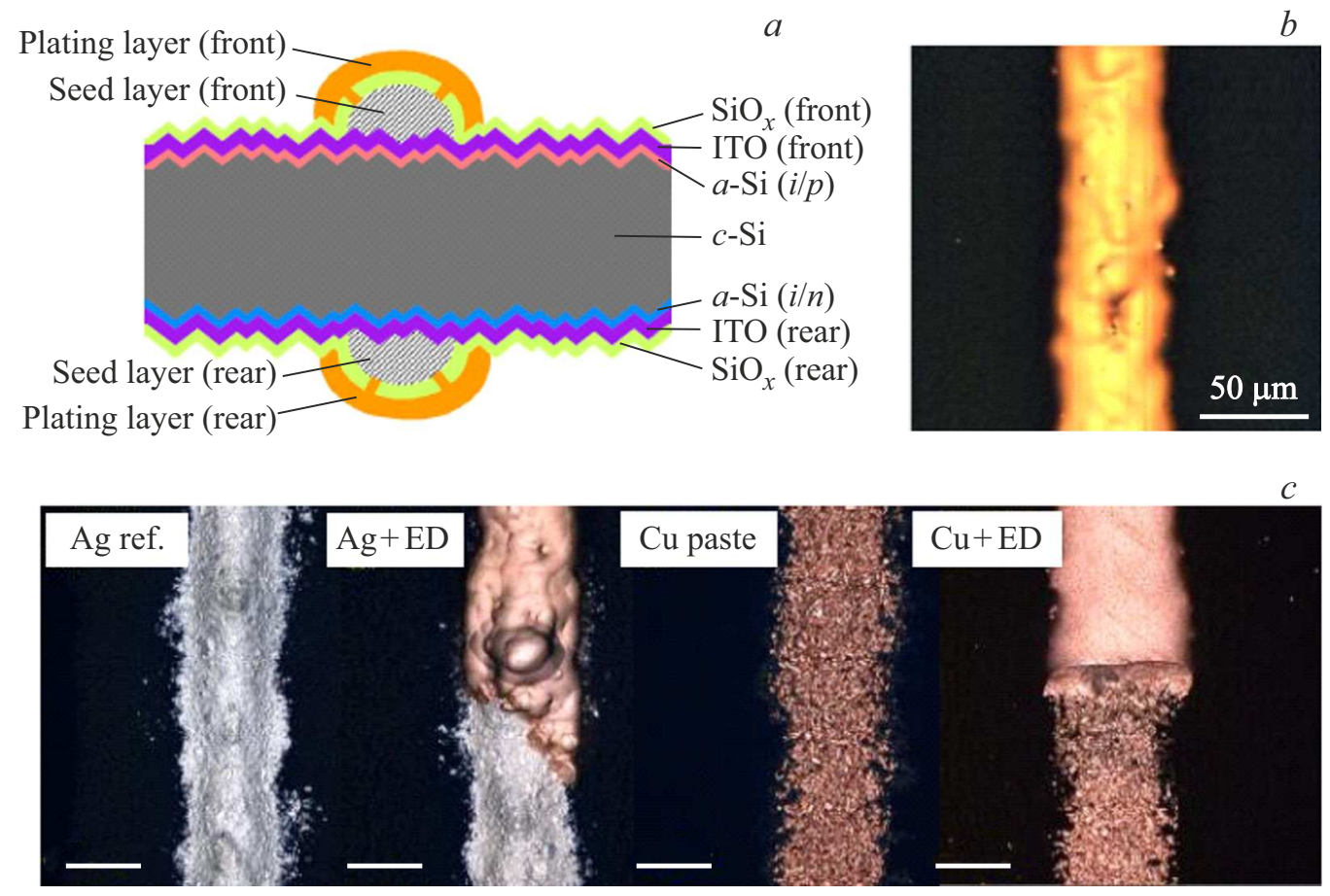

Рис. 3. $a-$ использование трафаретной печати для формирования затравочного слоя (seed layer), который первоначально задает геометрию контактной сетки для электрохимического осаждения. $b-$ процесс компании Kaneka [9]. $c$ - процесc CSEM с использованием Ag- и Сu-паст и SAM защитной маски [10].

Таблица 1. Прогресс в разработке SHJ ФЭП с медной контактной сеткой, осаждаемой электрохимическим методом

\begin{tabular}{|c|c|c|c|c|c|c|}
\hline Организация & Метод & Маска & $\begin{array}{c}\text { Ширина } \\
\text { фингеров, мкм }\end{array}$ & $\begin{array}{c}\text { Адгезия, } \\
\text { Н/мм }\end{array}$ & $\begin{array}{l}\text { Площадь } \\
\text { ФЭП, } \text { см }^{2}\end{array}$ & $\begin{array}{c}\text { Максимальный } \\
\text { кпд, \% }\end{array}$ \\
\hline Kaneka [9] & Screen-printing & $\mathrm{PECVD} \mathrm{SiO}_{x}$ & $45-55$ & l & $239(\mathrm{M} 2)$ & $20.8^{*}$ \\
\hline SunDrive [13] & Laser exposure & Dry/wet photoresist & 15 & l & 274 (M6) & 25.54 \\
\hline Silevo [14] & Laser exposure & Dry photoresist & 32 & / & $239(\mathrm{M} 2)$ & 23.1 \\
\hline EPFL/CSEM [10] & Laser ablation & $\mathrm{ALD} \mathrm{Al}_{2} \mathrm{O}_{3} / \mathrm{PECVD} a-\mathrm{Si}$ & $25-40$ & / & $235(\mathrm{M} 2)$ & 19.18 \\
\hline CSEM $[11]$ & Screen-printing & $\mathrm{ALD} \mathrm{Al}_{2} \mathrm{O}_{3}$ & $40-50$ & l & $222(\mathrm{M} 2)$ & 21.0 \\
\hline CSEM [19] & Inkjet printing & Hot melt ink & $25-30$ & 4 & $222(\mathrm{M} 2)$ & 24.73 \\
\hline Fraunhofer ISE [17] & $\mathrm{NaOH}$ Inkjet etch & $\mathrm{PVD} \mathrm{Al} / \mathrm{AlO}_{x}$ & $25-30$ & $0.5-2.3$ & $222(\mathrm{M} 2)$ & 22.1 \\
\hline Fraunhofer ISE [12] & Laser ablation & $\mathrm{PVD} \mathrm{Al} / \mathrm{AlO}_{x}$ & 25 & I & $244(\mathrm{M} 2)$ & 21.4 \\
\hline
\end{tabular}

Примечание. * Указана эффективность SНЈ модуля, а не ФЭП.

наиболее оптимальной формой является сечение контакта, изображенное на рис. 2.2, c. В настоящее время высота и ширина контактных дорожек при массовом производстве SHJ ФЭП с использованием трафаретной печати находятся на уровне 15-20 и 40-45 мкм соответственно, т. е. имеют аспектное соотношение $\mathrm{AR}=h / w \leq 0.5$, которое в принципе может быть увеличено до 1 путем использования метода двойной печати. Однако это приводит к повышенному расходу Ag-пасты, т.е. к повышению себестоимости SНЈ ФЭП.

Для снижения расхода $\mathrm{Ag}$, данный метод может использоваться для создания затравочного слоя (seed layer), формирующего геометрию контактной сетки, и дальнейшего роста меди на его поверхности сквозь тонкую диэлектрическую маску, как показано на рис. 3.
При этом в качестве маски может использоваться тонкая пленка оксида $\left(\mathrm{SiO}_{x}\right)$ или нитрида $\left(\mathrm{SiN}_{x}\right)$ кремния, осаждаемая с помощью метода плазмохимического осаждения из газовой фазы (PECVD) [9], или же ультратонкие $\mathrm{SAM}$ (self-assembled monolayer) и $\mathrm{Al}_{2} \mathrm{O}_{3}$ пленки [10,11].

Однако наличие тонкой защитной маски на поверхности ITO приводит к латеральному росту медного контакта в процессе электрохимического осаждения вдоль поверхности защитной маски, как схематически показано на рис. 2.2,a. Это в свою очередь приводит к потере адгезии контактной сетки к ITO, а также к уширению первоначальной Ag-контактной сетки, наносимой с помощью трафаретной печати. При этом размер уширения примерно равен удвоенной высоте медного контакта, т.е. при начальном размере, равном 25 мкм, 

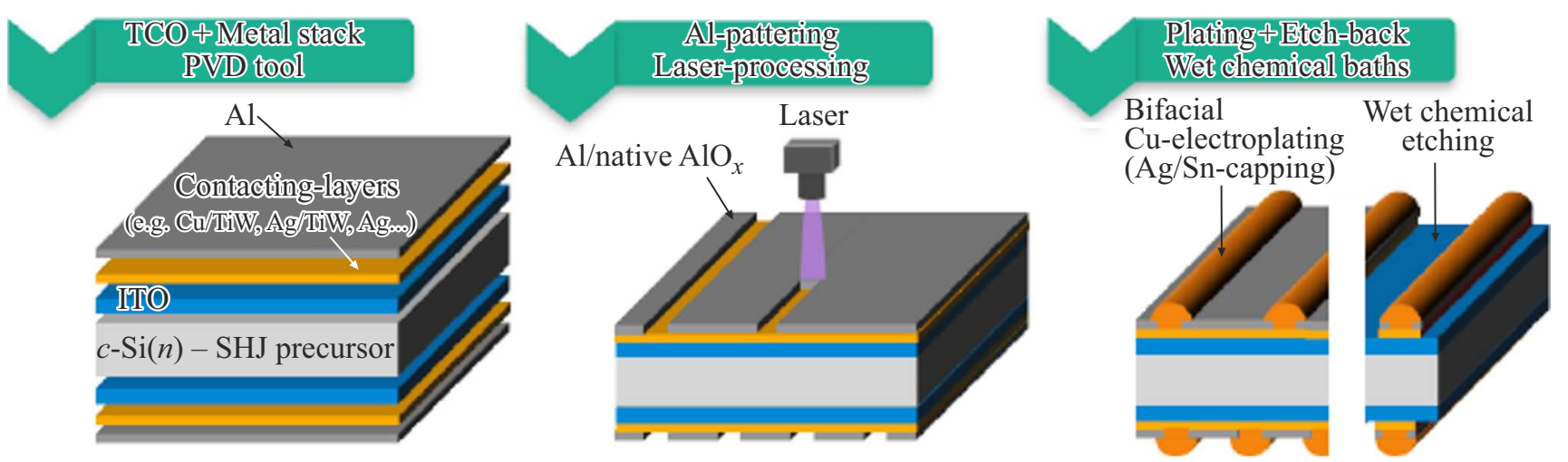

Pис. 4. Схематическое изображение NOBLE процесса с использованием лазерного экспонирования (абляции) для формирования рисунка контактной сетки, разработанного в Fraunhofer ISE [12].

ширина контактных дорожек после завершения процесса электрохимического осаждения будет $\sim 50$ мкм (см. табл. 1, Kaneka). Следует также подчеркнуть, что в большинстве исследований по формированию медной контактной сетки на поверхности SHJ ФЭП отсутствуют данные относительно ее адгезии к поверхности ITO слоев, как видно из табл. 1.

\section{2. Лазерное экспонирование}

Другим методом, который позволяет достаточно быстро сформировать рисунок контактной сетки на диэлектрической маске, является лазерное экспонирование. При этом лазер может быть использован непосредственно для удаления материала тонкой защитной диэлектрической маски, как показано на рис. 4. Преимуществом данного метода является возможность создания узких контактных дорожек (15-25 мкм, см. табл. 1) за счет малого диаметра лазерного луча. Однако данный метод имеет все те же недостатки использования тонкой маски в электрохимическом процессе, описанные выше. Более того, лазерное воздействие на поверхность SHJ ФЭП во время процесса удаления материала защитной маски (лазерная абляция) может приводить к появлению дополнительных поверхностных дефектов, т.е. к снижению кпд SHJ ФЭП. Как видно из табл. 1, в этом случае кпд не превышает $21.4 \%$, даже в случае использования фемто-секундных УФ лазеров [9], которые обладают наименьшим разрушающим воздействием.

Как показывает практика, использование толстого пленочного фоторезиста в комбинации с лазерным экспонированием позволяет достичь значительно более высоких показателей кпд SHJ ФЭП при использовании электрохимического осаждения контактов (табл. 1, SunDrive [13], Silevo [14]). Это связано с тем, что в этом случае происходит практически полное поглощение лазерного луча внутри фоточувствительного материала пленочного фоторезиста, для его локальной полимеризации (так называемая стадия экспонирования) с последующим удалением в емкости с проявителем (стадия
Таблица 2. Сравнение удельного сопротивления различных материалов для формирования контактных дорожек в $c$-Si $Ф Э П$

\begin{tabular}{l|c}
\hline \multicolumn{1}{c|}{ Материал } & $\begin{array}{c}\text { Удельное } \\
\text { сопротивление, } \\
\text { мкОм · см }\end{array}$ \\
\hline Чистое серебро $(\mathrm{Ag})$ & 1.6 \\
Высокотемпературная Ag-паста (РЕRC ФЭП) & $2-3$ \\
Низкотемпературная Ag-паста (SHJ ФЭП) & $4-5$ \\
Чистая медь (Cu) & 1.7 \\
Гальваническая медь & $1.8-2.6$ \\
100 нм PVD Сu-слой & $3-3.5$
\end{tabular}

проявления). Таким образом, в этом случае лазер не приводит к образованию дополнительных поверхностных дефектов и снижению эффективности SHJ ФЭП. Пленочный фоторезист является негативным и состоит из 3 слоев [15]: верхний полиэтиленовый (РЕТ) слой, внутренний фоточувствительный слой и нижний защитный полиэстеровый (PE) слой. Толщина пленочного фоторезиста может варьироваться от 10 до 100 мкм. В отличие от стандартных жидких фоторезистов, которые наносятся на поверхность образцов методом центрифугирования, пленочный фоторезист наносится с помощью ламинатора при температуре $100-150^{\circ} \mathrm{C}$, что делает данный метод приемлемым для использования на поверхности текстурированных SHJ ФЭП. При этом РЕT слой должен быть удален перед процессом ламинирования. Толстый пленочный фоторезист в комбинации с лазерным экспонированием позволяет достигнуть полностью вертикального рельефа и минимальной ширины медных контактных дорожек с $\mathrm{AR}=h / w>1$, как показано схематически на рис. 2.2, $c$, что может приводить к росту кпд SHJ ФЭП за счет увеличения тока короткого замыкания $\left(I_{s c}\right)$ и фактора заполнения $(F F)$. Последний зависит от сопротивления контактной сетки, которое прямо пропорционально ее удельному сопротивлению. Как видно из табл. 2, удельное сопротивление гальва- 


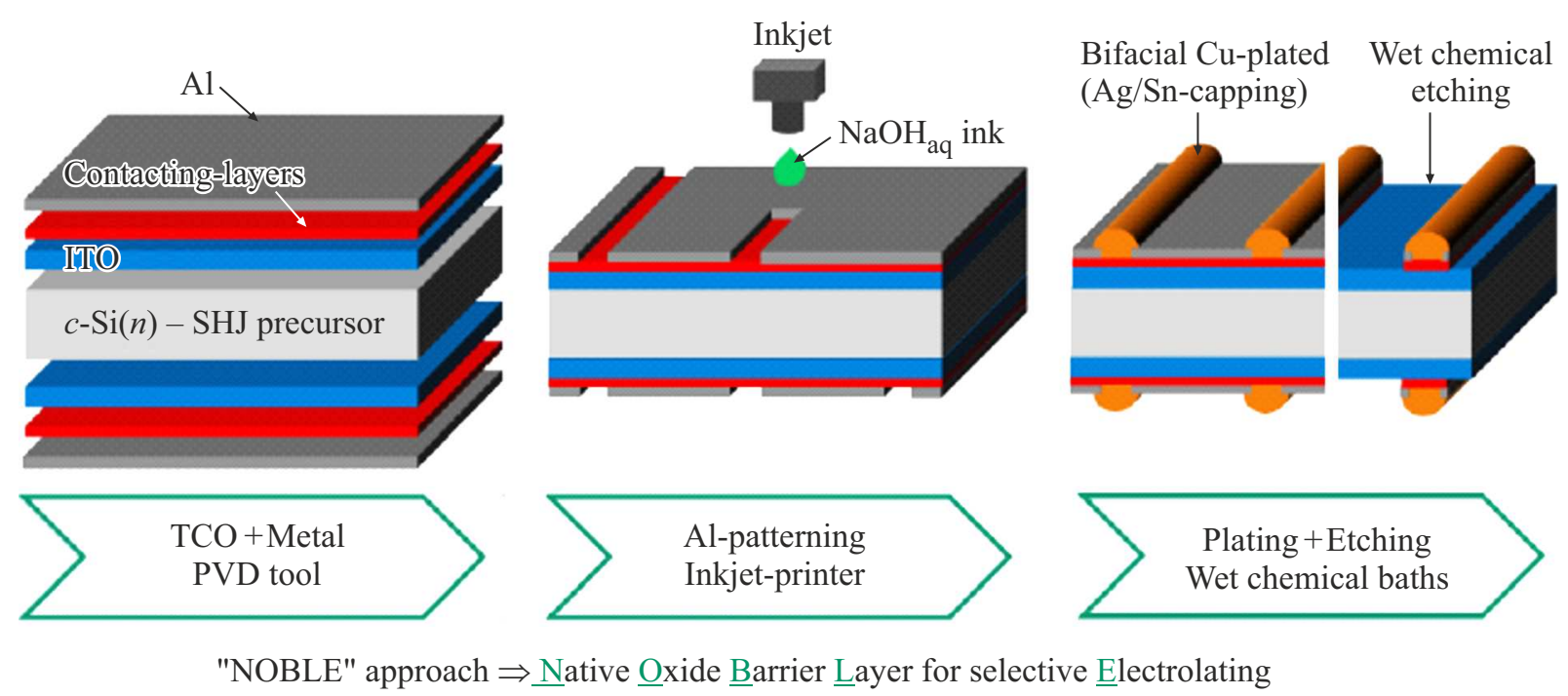

Рис. 5. Схематическое изображение NOBLE процесса, разработанного в Fraunhofer ISE с использованием щелочного травления для формирования рисунка контактной сетки с помощью струйного принтера [17].

нической меди примерно в 2 раза ниже сопротивления низкотемпературных Ag-паст, используемых в SHJ ФЭП при трафаретной печати.

Тем не менее стоит отметить, что процесс формирования защитной маски в данном случае является достаточно сложным и включает в себя несколько стадий:

1) предобработка поверхности пленочного фоторезиста, включая снятие РЕТ слоя;

2) ламинирование (может быть проблематичным при толщине SHJ ФЭП < 150 мкм);

3) лазерное экспонирование;

4) проявление;

5) сушка.

С другой стороны, стоимость пленочного фоторезиста на сегодняшний день составляет несколько $\$ / \mathrm{M}^{2}$, что делает данную технологию достаточно дорогостоящей.

\section{3. Струйная печать}

Струйная печать является наиболее простым методом для формирования защитной диэлектрической маски на поверхности SHJ ФЭП. При этом для достижения необходимой скорости обработки обычно используются пьезоэлектрические печатающие головки с рабочей частотой $\leq 10$ кГц [16]. Струйная печать может использоваться как в режиме удаления материала диэлектрической маски (аналогично лазерной абляции, рис. 4), так и в режиме ее нанесения. Достоинством первого метода является минимальное использование чернил, поскольку они используются непосредственно для создания рисунка контактной сетки, т.е. в этом случае маска является позитивной (рис. 5). Однако следует подчеркнуть, что использование тонкой защитной маски приводит к тем же проблемам, что и в случае трафаретной печати/лазерной абляции, - росту гальванической меди над поверхностью защитной пленки, т.е. к уширению контактных дорожек и потере адгезии (рис. 2.2,a).

С другой стороны, при формировании диэлектрической маски, состоящей из материала чернил (рис. 6), необходимо зарисовывать поверхность вне контактной сетки (негативная маска), т. е. практически всю поверх-

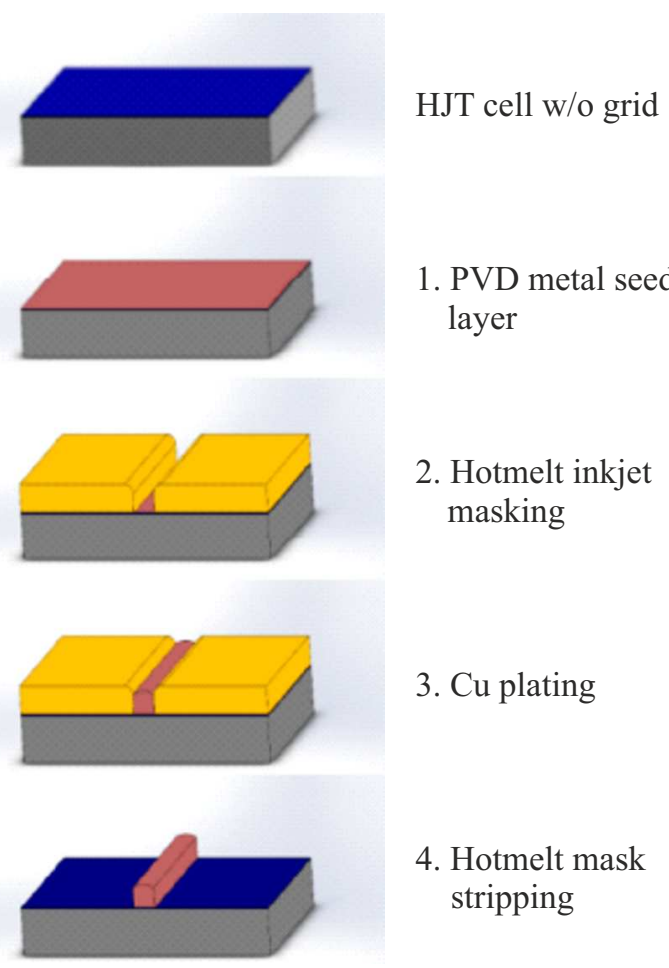

Рис. 6. Схематическое изображение электрохимического процесса, разработанного CSEM $[15,16]$, в котором геометрия контактной сетки задается с помощью струйной печати защитной маски из органического полимера. 
ность SHJ ФЭП, что наряду с ее микронной текстурой приводит к большому расходу чернил, поскольку толщина маски должна быть больше высоты пирамид на поверхности SHJ ФЭП ( $\leq 5$ мкм). Следует, так же отметить, что маска должна быть удалена после завершения процесса электрохимического осаждения (стадия 4 на рис. 6). Поэтому рентабельность данного метода определяется как стоимостью самих чернил, так и методом их утилизации. Согласно оценкам научноисследовательской группы CSEM, решением данной проблемы может быть использование достаточно дешевых чернил на основе органического полимера тугоплавких чернил (hot melt ink (HMI)) $[18,19]$.

Отличительной особенностью НМI масок является округлая форма стенок канавок, которые формируют медные контактные дорожки во время процесса электрохимического осаждения, как видно на рис. 2.2, $b$. Поэтому медные контактные дорожки по мере их роста могут начать расширяться, принимая форму стенок HМI маски, что приведет к повышенному затенению и падению $I_{s c}$. Очевидно, что радиус кривизны в данном случае определяется размером НMI капли и ее взаимодействием с поверхностью образца, которые зависят от таких параметров как вязкость чернил, диаметр сопла печатающей головки, температура чернил и образца, скорость печати и т.д. [16]. Цель данной работы подбор оптимальных параметров струйной печати с использованием НМI для формирования медных контактных дорожек с шириной $\leq 40$ мкм и определение их оптимальной высоты, чтобы минимизировать расход HMI, а также оптимизация их адгезионных свойств.

\section{3. Экспериментальные методы}

Для изготовления $\mathrm{SHJ}$ ФЭП использовались $c-\mathrm{Si}$ пластины с $n$-типом проводимости, размерами $157.35 \times 157.35 \mathrm{MM}$, с кристаллографической ориентацией $\langle 100\rangle$, выращенные методом Чохральского (CZ). Удельное сопротивление и толщина пластин составляли 1-3 Ом · см и 150 мкм соответственно. Предварительно пластины проходили стадии химического текстурирования и очистки поверхности. Для осаждения собственных и легированных слоев гидрогенизированного аморфного кремния $(a-\mathrm{Si}: \mathrm{H})$ использовались индустриальные VHF-PECVD реакторы (площадь реактора $130 \times 110 \mathrm{~cm}^{2}$, частота 40.68 МГц) [20]. На обе стороны SHJ ФЭП наносились ITO и металлические слои с использованием PVD системы Oxford PlasmalabSystem400. В качестве металлических слоев для достижения необходимой адгезии к ITO и латеральной проводимости тестировались различные комбинации из тонких $\mathrm{Ti}, \mathrm{Cr}$, $\mathrm{NiV}$ и $\mathrm{Cu}$ PVD слоев. Для формирования защитных диэлектрических HMI масок использовался струйный принтер PiXDRO LP50 (SUSS Microtec). В данных экспериментах использовались НМI на основе воска. Стадия электрохимического осаждения медной контактной сет- ки состояла из следующих этапов: 1) предварительная подготовка поверхности в растворах кислот для удаления загрязнений и окислов, 2) электрохимическое осаждение медных контактов в сернокислом электролите, 3) электрохимическое осаждение олова с использованием кислотных электролитов. Толщина формируемого Sn-покрытия составляла $\sim 1.5$ мкм, которое защищало медные контакты от окисления. Удаление с поверхности SHJ ФЭП диэлектрических НМІ масок осуществлялось в слабощелочных растворах и растворах растворителей, с последующим стравливанием металлических PVD слоев в растворах кислот.

Для сравнения была также изготовлена группа SHJ ФЭП со стандартной сеткой на основе низкотемпературной Ag-пасты, нанесенной методом трафаретной печати с использованием принтера (ASYS/EKRA E2) и имеющей высоту и ширину контактных дорожек около 15 и 40-45 мкм соответственно.

Измерения вольт-амперных характеристик (BAX), полученных SHJ ФЭП, проводились с помощью импульсного солнечного имитатора Pasan SpotLight HighCap (1.5 AM, $\left.25^{\circ} \mathrm{C}, 1 \mathrm{Sun}\right)$. Для анализа рельефа НMI масок и измерения высоты $\mathrm{Cu}$-контактных дорожек использовались оптический микроскоп Nikon Eclipse LV100 и стилусный профилометр AlphaStep D-120. Качество адгезии медных контактных дорожек измерялось с помощью граммометра Г-5.

\section{4. Результаты и обсуждение}

На рис. 7 показан эффект увеличения разрешающей способности (dpi) струйного принтера в направлении $X$ и $Y$, т.е. поперек и вдоль контактных дорожек соответственно, на форму канавок для роста медных гальванических контактов. Видно, что увеличение dpi в любом из направлений приводит к сужению канавки в защитной маске, т. е. к сужению $\mathrm{Cu}$-контактных дорожек, и их геометрия приобретает двояковогнутую форму. При этом высота защитной маски увеличивается из-за большего количества чернил, а скорость печати падает. С точки зрения минимизации оптических и электрических потерь в SHJ ФЭП необходимо стремиться к форме канавки, показанной в верхнем левом углу на рис. 7.

Для исследования влияния высоты $\mathrm{Cu}$-контактных дорожек (в англоязычной литературе, fingers) на параметры SHJ ФЭП использовалась геометрия контактной сетки с 4 токосъемными шинами (busbars (4BB)). При этом использовалась геометрия канавок в защитной НМІ маске, представленная на рис. 8. В этом случае ширина $\mathrm{Cu}$-контактной дорожки у ее основания изначально была равна $36 \pm 5$ мкм и увеличивалась по мере ее роста до величины > 50 мкм при высоте контактной дорожки $h>20$ мкм. Следует отметить, что высота пирамидального рельефа на поверхности SHJ ФЭП, который служит для снижения оптических потерь, находилась в 

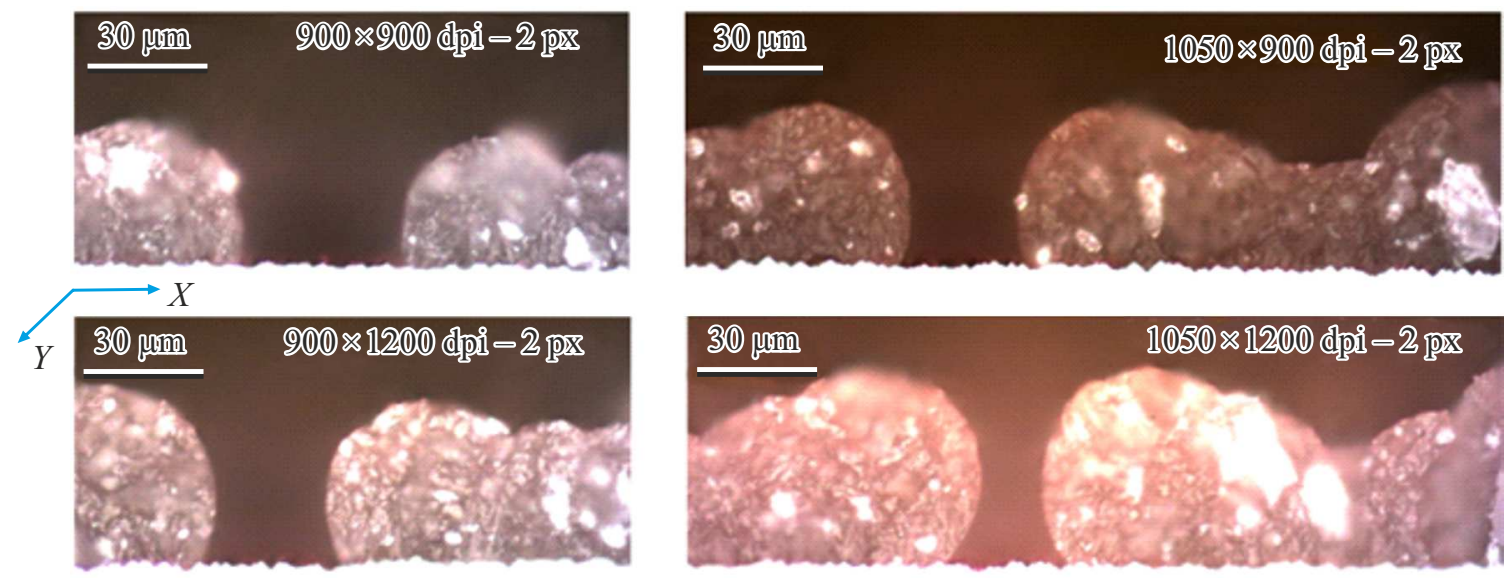

Рис. 7. Снимок поперечного сечения верхней стороны SHJ ФЭП после процесса нанесения защитной НМI маски струйным принтером в зависимости от разрешения печати. Показана область вблизи одной из канавок для гальванической контактной дорожки.

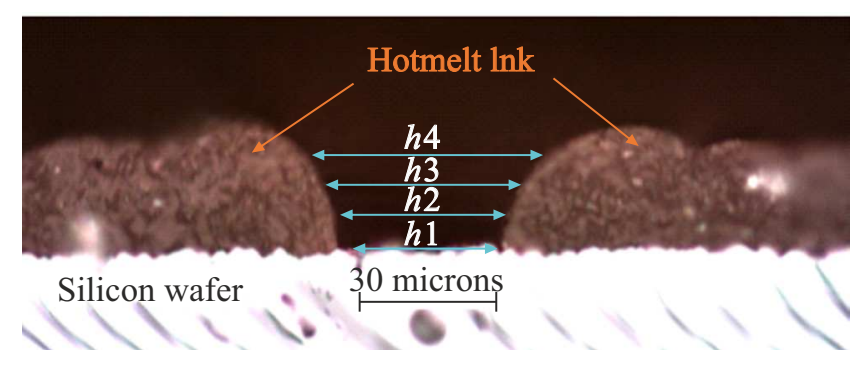

\begin{tabular}{c|c|c}
\hline Height & $\begin{array}{c}\text { Distance from } \\
c \text {-Si surface, } \mu \mathrm{m}\end{array}$ & $\begin{array}{c}\text { Mask opening } \\
\text { width, } \mu \mathrm{m}\end{array}$ \\
\hline h1 & 0 & 35.9 \\
h2 & 10 & 38.3 \\
h3 & 16 & 44.4 \\
h4 & 21 & 51.1
\end{tabular}

Рис. 8. Снимок поперечного сечения верхней стороны SHJ ФЭП после процесса нанесения защитной HMI маски струйным принтером. Показаны область вблизи одной из канавок для гальванической контактной дорожки и ее ширина (среднее значение) в зависимости от высоты.

диапазоне от 1 до 5 мкм, тогда как суммарная толщина ITO и металлических PVD слоев была равна 200 нм.

Результаты, представленные на рис. 9, показывают, что по мере увеличения высоты Сu-гальванических контактных дорожек с 9 до 22 мкм происходит в основном снижение $I_{s c}$ на $120 \mathrm{MA}$, что согласуется с результатами, представленными на рис. 8. Интересно, что $F F$ достигает максимального значения при высоте $\sim 12$ мкм, которая близка к оптимальной высоте для данной геометрии НМI маски, и практически не изменяется с ростом высоты. Это может говорить о том, что последовательное сопротивление в данном случае ограничено контактным сопротивлением промежуточных металлических слоев, используемых для улучшения латеральной проводимости и адгезии к ITO слоям. В зависимости от условий их нанесения и типа ITO измерения, основанные на методе TLM, показали, что контактное сопротивление $\left(\rho_{c}\right)$ для данных слоев лежит в диапазоне $10-30 \mathrm{MOM} \cdot \mathrm{cm}^{2}$, что согласуется с результатами, полученными другими исследователями [21]. Так как перед процессом гальванического нанесения $\mathrm{Cu}$-контактной сетки использовалась кислотная очистка, то можно предположить, что высокое контактное сопротивление вызвано не поверхностным оксидом, а контактом адгезионных металлических слоев к ITO. Данный факт также подтверждается сравнением BAX SHJ ФЭП, имеющих одинаковые $\mathrm{Cu}$ - и $\mathrm{Ag}$-контактные сетки, которые не имеют токосъемных шинок (busbarless - 0BB), с примерно одинаковым сечением контактных дорожек, изготовленных методом струйной и трафаретной печати соответственно. Как видно из табл. 3, SHЈ ФЭП со стандартной Ag-сеткой имеет более высокий $F F$ и низкое последовательное сопротивление $\left(R_{S}\right)$ по сравнению с $\mathrm{Cu}$-контактной сеткой. Тогда как площадь поперечного сечения их контактных дорожек является примерно одинаковой: $h \times w \times G F=12$ мкм $\times 30-35$ мкм $\times 1$ $=360-420$ мкм $^{2} \quad(G F-$ геометрический фактор $)$ и 15 мкм $\times 40-45$ мкм $\times 0.6=360-402$ мкм $^{2}$ для $\mathrm{Cu}-$ и Ag-контактных дорожек соответственно, а удельное сопротивление низкотемпературных $\mathrm{Ag}$-паст в $\sim 2$ раза выше, чем у гальванической меди (см. табл. 2). Поэтому для дальнейшего снижения $R_{s}$ и увеличения кпд $\mathrm{SHJ}$ ФЭП с Cu-контактной сеткой требуется дальнейшая оптимизация буферных металлических слоев с целью снижения их контактного сопротивления. Тем не менее кпд SHJ ФЭП с Cu-контактной сеткой на 0.3 абс.\% превышает кпд SHJ ФЭП с низкотемпературной Ag-сеткой 

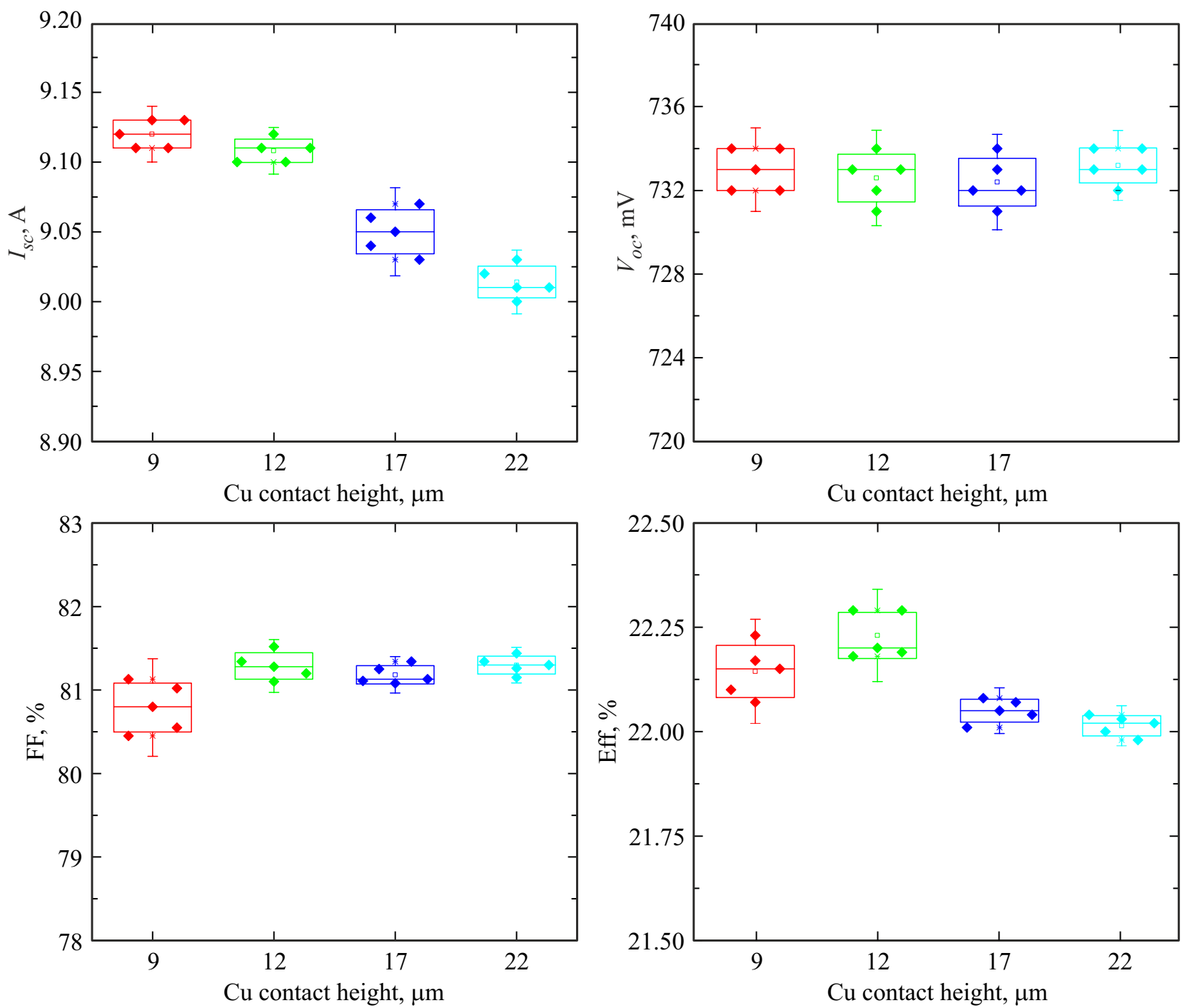

Рис. 9. Параметры SHJ ФЭП с медной контактной сеткой (4BB), изготовленных с использованием НМI маски, показанной на рис. 6, в зависимости от высоты Сu-контактных дорожек.

Таблица 3. Сравнение параметров SHJ ФЭП с гальваническими Cu- и трафаретными $\mathrm{Ag}-$ контактными сетками, имеющими одинаковую геометрию

\begin{tabular}{|c|c|c|c|c|c|c|}
\hline \multirow{2}{*}{ Тип контактной сетки } & \multirow{2}{*}{$\begin{array}{c}\text { Высота и ширина } \\
\text { контактных дорожек }\end{array}$} & \multicolumn{5}{|c|}{ Параметры SHJ ФЭП } \\
\hline & & $I_{s c}, \mathrm{~A}$ & $V_{o c}, \mathrm{~B}$ & $F F, \%$ & Eff., \% & $R_{s}, \mathrm{OM} \cdot \mathrm{cm}^{2}$ \\
\hline $\begin{array}{l}\text { Трафаретная серебряная } \\
\text { контактная сетка }(0 \mathrm{BB})\end{array}$ & $\begin{array}{c}h=15 \text { мкм, } \\
w=40-45 \text { мкм }\end{array}$ & 9.25 & 0.740 & 81.47 & 22.61 & 0.0049 \\
\hline $\begin{array}{l}\text { Сетка с медным гальваническим } \\
\text { покрытием (0ВB) }\end{array}$ & $\begin{array}{c}h=12 \text { мкм } \\
w=30-35 \text { мкм }\end{array}$ & 9.40 & 0.739 & 81.23 & 22.93 & 0.0045 \\
\hline
\end{tabular}

за счет снижения оптических потерь из-за более узких $\mathrm{Cu}$-контактных дорожек.

Дополнительным достоинством Сu-гальванических контактов является возможность их пайки при сборке SHJ модулей, тогда как большинство низкотемпературных Ag-паст является не паяемыми. При этом кри- тическим фактором, который определяет механические свойства контактов является их адгезия к ITO слоям на поверхности SHJ ФЭП. Результаты тестов с использованием тонкого ( $\leq 100-200 \mathrm{Hм}) \mathrm{Cu}$-слоя, осаждаемого на поверхность ITO слоев распылением $\mathrm{Cu}$-мишени в аргоновой атмосфере, показали его плохую адгезию к 
поверхности ITO $(<0.5 \mathrm{H} /$ мм $)$ после завершения процесса электрохимического осаждения. При этом уровень адгезии определялся с помощью пайки токосъемной шинки (шириной 1.0 мм) и ее последующем отрыве под углом $180^{\circ}$ (так называемый pull force test). Как показали результаты тестов, определенные комбинации $\mathrm{Ti}, \mathrm{Cr}$, $\mathrm{NiV}$ и $\mathrm{Cu} \mathrm{PVD}$ слоев могут приводить к уровню адгезии порядка $3-5 \mathrm{H} /$ мм, что существенно превосходит адгезию низкотемпературных паст к ITO (1.5-2 Н/мм) и является немаловажным при создании очень узких контактных дорожек $(w<30$ мкм).

\section{5. Заключение}

Показано, что струйная печать на основе органических чернил в комбинации с электрохимическим осаждением является перспективным методом для создания узких (< 40 мкм) медных контактных сеток на поверхности SHJ ФЭП. Тогда как использование тонких буферных металлических слоев, осаждаемых на поверхность ITO слоев методом магнетронного распыления, позволяет достичь превосходного качества адгезии гальванической меди к ITO (> $3 \mathrm{H} / \mathrm{Mm})$. С использованием данных методов были изготовлены полноразмерные $(157 \times 157$ мм $)$ двухсторонние SHJ ФЭП с Cu-контактной сеткой с кпд $=22.9 \%$. Для дальнейшего увеличения кпд необходима дальнейшая оптимизация процесса, направленная на снижение контактного сопротивления между ITO и буферными адгезионными слоями и оптимизацию формы канавок в защитной органической маске при дальнейшем уменьшении их ширины.

\section{Конфликт интересов}

Авторы заявляют, что у них нет конфликта интересов.

\section{Список литературы}

[1] R. Preu, E. Lohmuller, S. Lohmuller, P. Saint-Cast, J.M. Greulich. Appl. Phys. Rev., 7, 041315 (2020).

[2] A.S. Abramov, D.A. Andronikov, S.N. Abolmasov, E.I. Terukov. In: High Efficient Low-Cost Photovoltaics, Recent Developments, 2nd edn (Springer Nature, Switzerland, 2020) p. 113.

[3] K. Yoshikawa, H. Kawasaki, W. Yoshida, T. Irie, K. Konishi, K. Nakano, T. Uto, D. Adachi, M. Kanematsu, H. Uzu, K. Yamamoto. Nature Energy, 2, 17032 (2017).

[4] P.J. Verlinden. J. Renewable Sustainable Energy, 12, 053505 (2020).

[5] W. Wang. The mass production of HJT in Huasun, 4th Int. Workshop on Silicon Heterojunction Solar Cells (2021).

[6] J. Yu, J. Li, Y. Zhao, A. Lambertz, T. Chen, W. Duan, W. Liu, X. Yang, Y. Huang, K. Ding. Solar Energy Mater. \& Solar Cells, 224, 110993 (2021).
[7] S.K. Chunduri, M. Schmela. Heterojunction solar technology (TAIYANGNEWS Press release, 2020).

[8] D. Adachi, J.L. Hernandez, K. Yamamoto. Appl. Phys. Lett., 107, 233506 (2015).

[9] D. Adachi, T. Terashita, T. Uto, J.L. Hernandez, K. Yamamoto. Solar Energy Mater. \& Solar Cells, 163, 204 (2017).

[10] A. Dabirian, A. Lachowicz, J.W. Schüttauf, B. Paviet-Solomon, M. Morales-Masis, A. Hessler-Wyser, M. Despeisse, C. Ballif. Solar Energy Mater. \& Solar Cells, 159, 243 (2017).

[11] A. Lachowicz, G. Andreatta, N. Blondiaux, A. Faes, N. Badel, J.J.D. Leon, C. Allébe, C. Fontaine, P.-H. Haumesser, J. Jourdan, D. Muñoz, M Godard, M. Darmon, S. Nicolay, M. Despeisse, C. Ballif. Proc. IEEE 48th Photovoltaic Specialists Conf. (2021) p. 1530.

[12] T. Hatt, J. Bartsch, S. Schellinger, J. Schneider, A.A. Brand, S. Kluska, M. Glatthaar. Proc. 38th Eur. Photovoltaic Solar Energy Conf. (2021) p. 326.

[13] Patent WO 2016/000030, https://www.pv-magazine.com/ 2021/09/10/austaralian-startup-sets-25-54-efficiency-recordfor-silicon-cell

[14] J.B. Heng, J. Fu, B. Kong, Y. Chae, W. Wang, Z. Xie, A. Reddy, K. Lam, C. Beitel, C. Lioa, C. Erben, Z. Huang, Z. Xu. IEEE J. Photovoltaics, 5, 82 (2014).

[15] DuPont ${ }^{\mathrm{TM}}$ Riston special series data sheet \& processing information

[16] D. Stüwe, D. Mager, D. Biro, J.G. Korvink. Inkjet Technology for Crystalline Silicon Photovoltaics, 27, 599 (2015).

[17] T. Hatt, J. Bartsch, S. Kluska, S. Nold, S.W. Glunz, M. Glatthaar. Proc. IEEE 47th Photovoltaic Specialists Conf. (2020) p. 397.

[18] A. Lachowicz, A. Descoeudres, J. Champliaud, A. Faes, J. Geissbuhler, M. Despeisse, S. Nicolay, C. Ballif. Proc. 36th Eur. Photovoltaic Solar Energy Conf. (2019) p. 564.

[19] A. Lachowicz, P. Wayss, J. Geissbuhler, A. Faes, J. Champliaud, N. Badel, C. Ballif, M. Despeisse. Review on plating processes for silicon heterojunction cells, 8th Workshop on Metallization and Interconnection for Crystalline Silicon Solar Cells ( 2019).

[20] S. Abolmasov, A. Abramov, D. Andronikov, K. Emtsev, G. Ivanov, I. Nyapshaev, D. Orekhov, A. Semenov, G. Shelopin, E. Terukov, B. Strahm, G. Wahli, P. Papet, T. Söderström, Y. Yao, T. Hengst, G. Kekelidze. Proc. 31th Eur. Photovoltaic Solar Energy Conf. (2015) p. 1046.

[21] A. Aguilar, S. Herasimenka, J. Karas, H. Jain, Jongwon Lee, K. Munoz, L. Michaelson, T. Tyson, W. Dauksher, S. Bowden. Proc. IEEE 43rd Photovoltaic Specialists Conf. (2016) p. 972.

Редактор А.Н. Смирнов 


\title{
Formation of a copper contact grid on the surface of silicon heterojunction solar cells
}

\author{
S.N. Abolmasov ${ }^{1}$, A.S. Abramov ${ }^{\mathbf{1 , 2}}$, V.N. Verbitskii ${ }^{\mathbf{1 , 2}}$,
} G.G. Shelopin ${ }^{1}$, A.V. Kochergin ${ }^{1,3}$, E.I. Terukov ${ }^{1,2,3}$

${ }^{1}$ Research and development center for thin-film technologies in energetics, 194064 St. Petersburg, Russia

${ }^{2}$ loffe Institute, 194021 St. Petersburg, Russia

${ }^{3}$ St. Petersburg Electrotechnical University „LETI“, 197376 St. Petersburg, Russia

Abstract A comparative analysis of various methods of forming a copper $(\mathrm{Cu})$ contact grid on the surface of silicon heterojunction solar cells (SHJ SC) as an alternative to the standard screen printing method using expensive silver-containing $(\mathrm{Ag})$ pastes is presented. It has been shown that the use of inkjet printing for the formation of protective dielectric masks based on an organic polymer and thin buffer metal layers for the growth of a $\mathrm{Cu}$ contact grid by electroplating makes it possible to form a contact grid of the required shape and having sufficient adhesion to the surface of SHJ SC. Using this method, doublesided SHJ SC (size $157 \times 157 \mathrm{~mm}$ ) with $\mathrm{Cu}$ contact mesh were fabricated, demonstrating an efficiency of $22.9 \%$ and an adhesion level of $3-5 \mathrm{~N} / \mathrm{mm}$ compared to $22.6 \%$ and $1.5-2 \mathrm{~N} / \mathrm{mm}$ using a similar contact mesh based on Ag paste. 